\title{
A QUEM CABE A PROTEÇÃO DO VULNERÁVEL? AS CONTRIBUIÇÕES DOS MOVIMENTOS SOCIAIS DA DÉCADA DE 1990 NA LUTA PELA GARANTIA DOS DIREITOS DE CRIANÇAS E ADOLESCENTES
}

\author{
Émina Márcia Nery dos Santos ${ }^{1}$ \\ https://orcid.org/0000-0003-1532-270X \\ Andréa Márcia Monteiro Ferreira² \\ https://orcid.org/0000-0002-1871-201X
}

RESUMO: o texto objetiva analisar as contribuições dos movimentos sociais na década de 1990 para a instituição dos direitos das crianças e dos adolescentes no Brasil, em especial, no que diz respeito ao Estatuto da Criança e do Adolescente (ECA). O estudo resulta de revisão bibliográfica, acompanhada da análise de conteúdo, a partir de entrevista realizada com o Padre Bruno Sechi, na qual se evidenciou que as políticas públicas de atendimento na área da infância e da adolescência evoluíram consideravelmente a partir do ECA, mas, ainda são desafios para o poder público e a sociedade civil. Considera que esses direitos podem ser consolidados com a criação de uma rede de proteção social que articule ações entre diferentes campos, efetivando o atendimento das crianças e dos adolescentes no que diz respeito aos direitos inerentes à existência humana.

PALAVRAS-CHAVE: movimentos sociais, direitos das crianças e dos adolescentes, políticas públicas.

\footnotetext{
${ }^{1}$ Doutora em Ciências Sócio Ambientais pelo Núcleo de Altos Estudos Amazônicos da Universidade Federal do Pará (NAEA/UFPA). Professora Titular da Universidade Federal do Pará (UFPA),Belém, Pará, Brasil. emina@ufpa.br

${ }^{2}$ Mestranda pelo Programa de Pós-Graduação em Currículo e Gestão da Escola Básica da Universidade Federal do Pará (PPEB/UFPA).Professora da Secretaria Municipal de Educação (SEMEC) de Belém (PA),Belém, Pará, Brasil.and.gel28@yahoo.com.br
} 
WHO WILL PROTECT THE VULNERABLE? THE CONTRIBUTIONS OF

THE SOCIAL MOVEMENTS OF THE 1990S IN THE FIGHT FOR THE GUARANTEE OF THE RIGHTS OF CHILDREN AND ADOLESCENTS

ABSTRACT: the text aims to analyze the contributions of the social movements in the 1990s to the institution of the rights of children and adolescents in Brazil, especially with regards to the Statute of the Child and the Adolescent (Estatuto da Criança e do Adolescente - ECA). The study results from a bibliographical review, accompanied by content analysis, based on an interview with Father Bruno Sechi, which shows that the public policies of protection in the area of childhood and adolescence evolved considerably from the ECA, but, there are still challenges for public power and civil society. It considers that these rights can be consolidated with the creation of a network of social care that articulates actions between different fields, effecting the protection of children and adolescents with respect to the rights inherent in human existence.

KEYWORDS: social movements, rights of children and adolescents, public policies.

\section{¿A QUIEN CABE LA PROTECCIÓN DEL VULNERABLE? LAS CONTRIBUCIONES DE LOS MOVIMIENTOS SOCIALES DE LA DÉCADA DE 1990 EN LA LUCHA POR LA GARANTÍA DE LOS DERECHOS DE NIÑOS Y ADOLESCENTES}

RESUMEN: el texto objetiva analizar las contribuciones de los movimientos sociales en la década de 1990 para la institución de los derechos de los niños y adolescentes en Brasil, en especial, en lo que se refiere al Estatuto del Niño y del Adolescente (Estatuto da Criança e do Adolescente - ECA). El estudio resulta de revisión bibliográfica, acompañada del análisis de contenido, a partir de una entrevista realizada con el Padre Bruno Sechi, en la cual se evidenció que las políticas públicas de protección en el área de la niñez y la adolescencia evolucionaron considerablemente a partir del ECA, todavía, hay desafíos para el poder público y la sociedad civil. Considera que esos derechos pueden ser consolidados con la creación de una red de atención social que articule acciones entre diferentes campos, efectuando la protección de los niños y de los adolescentes en lo que se refiere a los derechos 
inherentes a la existencia humana.

PALABRAS CLAVE: movimientos sociales, derechos de los niños y de los adolescentes, políticas públicas.

\section{Introdução}

O Estatuto da Criança e do Adolescente (ECA), Lei no 8.090/1990 (BRASIL, 1990), regulamentou o direito da criança e do adolescente sob o paradigma da Proteção Integral, representando um importante avanço do ponto de vista democrático, já que institui as conquistas relativas aos direitos dessa população, promulgados na Constituição Federal de 1988, por meio do artigo 227, o qual consagra a premissa da proteção integral a esses segmentos (BRASIL, 1988).

Costa ratifica esse posicionamento:

De modo específico, os artigos 227 e 288 tratam da proteção especial das crianças e adolescentes. Portanto, além da explicitação normativa da condição peculiar em que se encontram, como pessoas em desenvolvimento, ao positivar tais direitos, o texto constitucional chama atenção para o tratamento prioritário que deve receber o público de crianças e adolescentes, como estratégia na efetivação de uma outra realidade social para essa parcela da população (2012, p. 12).

A Carta Constitucional assumiu a dignidade humana como princípio reitor e unificador da efetivação de direitos fundamentais (COSTA, 2012, p. 143), definindo crianças e adolescentes como sujeitos de direitos e responsabilizando o Estado, a família e a sociedade civil pela sua efetivação. De forma incontroversa, denota-se um avanço da Constituição brasileira, buscando superar o paradigma menorista pautado na "doutrina da situação irregular", a fim de se efetivar a proteção integral como princípio da dignidade humana de caráter normativo, garantindo-Ihes o direito a um desenvolvimento integral em condições de liberdade e dignidade.

Internacionalmente, a temática ganhou destaque com o texto da Convenção das Nações Unidas Sobre os Direitos das Crianças e dos Adoles- 
centes, aprovado em 1989. Pereira conta que "a Convenção é resultado de onze anos de trabalho e discussão entre representantes de diversos países para estabelecer os direitos humanos comuns a todas as crianças, capazes de abranger as diferentes conjunturas sócio-culturais existentes entre os povos" (1998, p. 84). Após essa convenção, houve um maior embasamento para a formulação de normativas legais internacionalmente aplicáveis, com vistas a abranger todas as crianças e adolescentes, sem qualquer tipo de distinção (PEREIRA, 1998, p. 85).

Para Pini (2015), o ECA afirma o valor intrínseco da criança como ser humano, a sua condição de sujeito de direitos e o valor prospectivo da infância e da juventude, além definir esses indivíduos como portadores de continuidade de seu povo, de sua família e da espécie humana. A autora enfatiza que Estado, sociedade, em geral, família e comunidade têm o dever de reconhecer sua condição peculiar de desenvolvimento, para que seja possível assegurar condições dignas para sua formação como indivíduo.

Nesse sentido, o ECA, no Capítulo IV, "O Direito à Educação, à Cultura, ao Esporte e ao Lazer", determina:

Art. 53. A criança e o adolescente têm direito à educação, visando ao pleno desenvolvimento de sua pessoa, preparo para o exercício da cidadania e qualificação para o trabalho, assegurando-se lhes:

I - igualdade de condições para o acesso e permanência na escola;

II - direito de ser respeitado por seus educadores;

III - direito de contestar critérios avaliativos, podendo recorrer às instâncias escolares superiores;

IV - direito de organização e participação em entidades estudantis;

$\mathrm{V}$ - acesso à escola pública e gratuita próxima de sua residência (BRASIL, 1990, art. 53).

Esse marco legal também normatizou a obrigatoriedade da matrícula na rede regular de ensino, a qual é de responsabilidade dos pais; cabendo aos dirigentes dos estabelecimentos escolares informar ao Conselho Tutelar as faltas injustificadas, possíveis maus-tratos e elevados níveis de repetência, sempre respeitando o contexto socioeconômico, cultural e artístico no qual a criança está inserida.

Vale esclarecer que o ECA se divide em dois livros. O primeiro faz referência aos direitos fundamentais das crianças e adolescentes, trazendo 
garantias relativas à sobrevivência e ao desenvolvimento social e pessoal. Já o segundo livro, intitulado "Parte Especial", prima pela garantia dos direitos à integridade física, psicológica, moral e social, tratando do planejamento e execução de ações de proteção especial através de programas de proteção socioeducativos (orientação e apoio sócio familiar, apoio socioeducativo em meio aberto, colocação familiar, liberdade assistida, semiliberdade e internação), realizados tanto por entidades governamentais quanto pelas não-governamentais (BRASIL, 1990).

Conforme o artigo 86 do ECA, a política de atendimento aos direitos da criança e do adolescente deve ser realizada por meio de um conjunto articulado de ações governamentais e não-governamentais, da União, dos estados, do Distrito Federal e dos municípios. Assim, foram criadas novas modalidades de articulação entre o Estado e a sociedade civil, a fim de assegurar "o atendimento e garantia de direitos, por meio da proteção integral, da vigilância e da desresponsabilização pelo não atendimento, atendimento irregular ou violação de direitos individuais ou coletivos" (MARTINS, 1991, p. 66). Essa dinâmica incorporou a participação das Secretarias de Segurança Pública, do Ministério Público, dos Conselhos de Direito da Criança e do Adolescente, de Organizações Não Governamentais (ONGs), entidades e associações legalmente constituídas, que, juntamente com a sociedade civil, se tornaram instrumentos de democratização e ampliação da cidadania em prol dos direitos das crianças e adolescentes no país.

Destaca-se, também, que o Fundo das Nações Unidas para a Infância (UNICEF), em relatório de $2015^{3}$, avaliou os 25 anos de institucionalização do ECA, descrevendo-o como uma das legislações mais avançadas no mundo, principalmente, no que diz respeito à defesa da cidadania e garantia de direitos (FUNDO DAS NAÇÕES UNIDAS PARA A INFÂNCIA, 2015). Isso contribuiu significativamente para a formulação do princípio da garantia universal dos direitos das crianças e dos adolescentes, servindo como referência para os países da América Latina - primeiro, pela sua coerência com os direitos humanos; segundo, pelo respeito à fase de desenvolvimento característica dessa idade. $\mathrm{O}$ documento ainda menciona que o ECA representou avanços nas áreas da educação, da saúde e da proteção. Entretanto, ainda há uma série de desafios a enfrentar para, efetivamente, incluir por meio de políticas públicas a população infanto-juvenil desfavorecida economicamente e marginalizada.

\footnotetext{
${ }^{3}$ O relatório \#ECA25anos: avanços e desafios para a infância e a adolescência (FUNDO DAS NAÇÕES UNIDAS PARA A INFÂNCIA, 2015) apresenta uma análise de indicadores relacionados à infância e à adolescência desde a aprovação do ECA, em 1990.
}

Rev. Fac. Educ. (Univ. do Estado de Mato Grosso), Vol. 31, Ano 17, № 1, p. 35-56, jan./jun., 2019 
A promulgação do ECA resultou de ampla mobilização social, que contou com a participação efetiva de diferentes setores da sociedade civil se articulando em torno de um objetivo comum: "justiça social, cidadania e liberdades democráticas influindo decisivamente no processo de transição democrática no pais" (PEREIRA, 1998, p. 30), frente à repressão e à violação de direitos instituídos pela população durante a ditadura militar. É sobre essas circunstâncias que este artigo se detém.

O clima institucional vivenciado no país na década de 1970 apresentava, de um lado, a forte intervenção do Estado, violando de forma ostensiva a população com a retração de direitos, condições socioeconômicas desiguais, ausência de políticas sociais, entre outros. De outro lado, estava a resistência de movimentos sociais por espaços de debates políticos que reivindicassem emprego, saúde, moradia, educação, igualdade dos direitos, da mulher, da criança, dos negros, dos homossexuais, dos idosos, reforma agrária, sustentabilidade ambiental, segurança e melhores condições de vida nas grandes cidades, dentre outros.

Sobre esse período, é importante frisar a ação dos movimentos sociais que lutaram em defesa dos direitos das crianças e dos adolescentes no regime militar, durante o qual os direitos civis e políticos foram fortemente atingidos, pois, os atos institucionais foram utilizados para a repressão legal, enquanto os direitos políticos de grande parte de líderes políticos, sindicais, intelectuais e militantes foram cassados. Assim, os sindicatos sofreram duras intervenções, o que ocasionou o fechamento de muitos órgãos da cúpula do movimento operário (XAVIER, 2008, p. 41).

Este trabalho, entretanto, tem como foco o movimento da sociedade civil referente ao processo de institucionalização do ECA. A discussão parte da seguinte questão: como as lutas e as reivindicações da sociedade civil organizada impulsionaram a criação do ECA?

Trata-se de problemática relevante na medida em que, no Código de Menores (BRASIL, 1979), a criança e o adolescente eram concebidos como "menor em situação irregular", devido à sua situação de pobreza, carência e abandono. Assim, tornavam-se alvo de medidas protetivas e vigilantes, por meio de instrumentos judiciais nos quais não havia espaço para o diálogo e participação de setores sociedade civil que se preocupassem com a situação dessa população. Além disso, o poder era altamente centralizador e repressor, ficando a cargo da polícia, dos juristas e administradores.

O texto analisa os argumentos sistematizados por meio de revisão bibliográfica e análise de conteúdo a partir da entrevista com o Padre Bruno 
$\mathrm{Sechi}^{4}$, concedida às pesquisadoras no ano de 2018 . No que diz respeito à sua estrutura, primeiro, discute alguns aspectos da história das políticas de atendimento a crianças e adolescentes no Brasil dos anos 1980, a partir do debate entre menoristas e estatutistas; em seguida, trata da mobilização da sociedade civil na luta pela aprovação do ECA, com destaque para o protagonismo da Republica do Pequeno Vendedor, em Belém (PA). Por fim, as considerações finais trazem uma reflexão sobre as perspectivas atuais do atendimento às crianças e adolescentes no país.

\section{A mobilização da sociedade civil e o avanço dos direitos da criança e do adolescente}

As intervenções dos movimentos sociais estiveram presentes em diferentes períodos durante os conflitos ocorridos no século XX. No Brasil, eles se consolidaram e promoveram mudanças significativas na realidade política, econômica e social. Constituíram, assim, uma relevante estratégia de luta pela conquista e ampliação dos direitos sociais, principalmente, no que se refere à valoração individual e coletiva das crianças e dos adolescentes. Todos esses eventos fomentaram a visibilidade desses segmentos em nossa sociedade, diante do que Costa (2012) denomina como hierarquia valorativa invisível, a qual os desqualifica como subprodutos e subcidadãos, indivíduos e grupos precarizados e socialmente vulneráveis.

Em meados da década de 1980, período em que o país vivenciou o processo de abertura política que antecedeu a instalação da Assembleia Nacional Constituinte, esses movimentos se articularam e organizaram várias frentes de luta pela infância brasileira. Dentre elas, merece destaque a criação do Fórum Nacional pelos Direitos da Criança e do Adolescente (Fórum DCA), cujo objetivo foi promover a alteração e a reformulação do Código de Menores e fazer "o reordenamento institucional dos organismos responsáveis pela operacionalização e atendimento de crianças e jovens" (PEREIRA, 1998, p. 29). Para isso, foram criadas comissões de trabalho, em que se discutiu os direitos das crianças e dos adolescentes, constituindo um grupo de redação do estatuto que sistematizava reivindicações relativas a essa população e as formatava aos moldes legais. A partir desse processo, se constituía uma proposta bem

\footnotetext{
${ }^{4}$ Padre salesiano, nascido na Itália, naturalizado brasileiro; foi um dos fundadores, em 1970, da República do Pequeno Vendedor (atualmente Movimento República de Emaús), em Belém do Pará. Coordenou o Fórum Nacional DCA, e coordena a Rede Nacional dos Centros de Defesa dos Direitos da Criança e do Adolescente. Trata-se de uma figura política muito importante no movimento de implementação das políticas que concebem criança e adolescente como sujeitos de direitos na Amazônia e no país.
} 
fundamentada que saiu vitoriosa no parlamento e deu origem à política de proteção integral instituída no ECA ${ }^{5}$.

O conceito de movimentos sociais que se adota neste texto é o de sociedade civil, "usado para denominar tecnicamente a organização e movimentos feitos por pessoas e pela sociedade" (SANTOS, 2004, p. 17). Este é visto como um conceito amplo que pode incorporar, de acordo com os critérios de análise utilizados, organizações voltadas para ações de interesses coletivos morais, éticos, políticos, ideológicos, entre outros. Envolve, também, instituições como escola, igreja, família, sindicatos, movimentos socais, associações de classe, meios de comunicação, ONGs... Esse conjunto de mobilizações da sociedade civil ressurge nesse período contra a ofensiva do Estado, unindo os movimentos na luta pela garantia dos direitos das crianças e dos adolescentes no país.

Ainda naquela época, se observou um significativo agravamento do número de crianças e adolescentes em situação de risco, abandonados nas ruas e em outros estados de vulnerabilidade. Além disso, em meio ao descaso e à omissão do poder público diante da violação de direitos, também eram constantes as denúncias de violência nos internatos e nas ruas. De acordo com Volpi,

A existência de crianças desnutridas, abandonadas, maltratadas, vítimas de abuso, autoras de atos infracionais e outras violações era atribuída a sua própria índole, enquadrando-se todas numa mesma categoria ambígua e vaga denominada situação irregular. Estar em situação irregular significava estar à mercê da Justiça de Menores cuja responsabilidade misturava de forma arbitrária atribuições de caráter jurídico com atribuições de caráter assistencial (2001, p. 33).

Dessa forma, durante a ditadura militar, o aparato legal destinado à infância e à adolescência no Código de Menores estabelecia que, devido à sua condição socioeconômica (pobre, negro, morador de rua, marginalizado...), o menor "irregular" não tinha direito de acesso a políticas públicas que proporcionassem condições de vida digna e favoráveis ao seu desenvolvimento integral como pessoa humana. Lamentavelmente, a legislação nesse período

\footnotetext{
${ }^{5}$ Segundo Pereira (1998, p. 30), essa articulação em nível nacional se deu por meio de centenas de encontros, congressos, assembleias, seminários, reuniões, jornadas em todo o país, com adesão de várias articulações estaduais e municipais que, mais tarde, acabaram criando os fóruns regionais, à luz do Fórum Nacional DCA.
} 
considerava a pobreza uma ameaça à ordem social vigente.

Nesse contexto, o Código de Menores, também denominado Código Mello Mattos, criado em 1927, surge para assistir aos "menores", "abandonados e delinqüentes", com dezoito anos incompletos, com princípios pautados em premissas autoritárias e repressivas. O propósito era de estabelecer o controle institucional, haja vista que, desde a década de 1920, já se organizavam no país internações da população infanto-juvenil em estabelecimentos oficiais - sobretudo, porque a concepção hegemônica de infância nesse período se remetia ao slogan de "criança infratora" (MORAES; CARVALHO, 2002).

Sobre o Código de Menores, no ano de 1979, foi substituída a legislação de menores abandonados e delinquentes instituída em 1927 pela nova Lei $n^{\circ}$ 6.697/1979 (BRASIL, 1979), legitimadora da Doutrina da Situação Irregular. Nela, foram estabelecidas novas medidas de proteção, vigilância e assistência aos menores. No entanto, a ideia sobre a situação de vulnerabilidade socioeconômica da infância se manteve fundamentada na pobreza como um desvio de conduta que precisava ser reparado. Esse Código se destinava à proteção, assistência e vigilância dos menores de 18 anos que se encontrassem em situação irregular, como: "I - privado de condições essenciais à sua subsistência [...]; II - vítima de maus-tratos [...]; III-em perigo moral [...]; IV - privado [...] dos pais ou responsável [...]; V - Com desvio de conduta [...]; VI - autor de infração penal [...]" (BRASIL, 1979, art. 2).

Para Moraes e Carvalho,

O Código de Menores tinha um caráter assistencial-repressivo, ou seja, sua política era "proteger" o "menor pobre e abandonado" e reprimir o "delinqüente". O Código também mencionava os direitos de todas as crianças e adolescentes e não considerava outras instituições presentes no universo infantil e jovem, como a família e a escola. De fato, a criança e o adolescente, que não estivessem em uma situação "irregular" não chegavam a ser por ele amparados. Pode-se dizer que, para o Código de Menores, interessava juridicamente as consequências dessa situação: uma criança abandonada iria perambular pelas ruas ou praticar algum delito. Em ambos os casos, eram aplicadas as "medidas tutelares" de recolhimento, para uma assistência tutelada pelo Estado ou para uma medida repressiva, porém o que havia era a privação dos direitos desses jovens e, de certo modo, presumia-se que acabava aí o incômodo social (2002, p. 5). 
Desta feita, a instituição da doutrina de situação irregular foi duramente criticada, principalmente, pela sociedade civil organizada, já que relacionava problemas de ordem econômica à personalidade das crianças e adolescentes, que não conseguiam se adaptar ao padrão de homogeneidade instituído histórica e culturalmente (COSTA, 2012), supostamente comprometendo com isso o desenvolvimento harmônico da sociedade. Todavia, eles são por essa mesma lógica colocados à margem da sociedade, em uma miséria que "não é apenas econômica, mas emocional, existencial e política, produzindo sentimentos individuais e coletivos de falta de pertencimento social, de inferioridade e de responsabilidade individual pela própria condição" (MACIEL, 2006, p. 30).

A essência discursiva do conteúdo dessa doutrina não diferenciava o menor infrator daquele que estava em situação de abandono, maus-tratos, dentre outras. Nesse contexto, crianças e adolescentes foram rotulados normativamente como sujeitos que incomodavam a ordem estabelecida, que precisam ser recuperados e educados, para se qualificarem e serem aceitos na sociedade. Entretanto, até então, ainda não estavam amparados pela legislação enquanto sujeitos de direitos.

Ainda no final da década de 1970 e início da década de 80 - devido ao aumento das desigualdades socioeconômicas, ao desordenado crescimento demográfico da população infanto-juvenil ${ }^{6}$, dentre outras questões, juntamente com a saída desses jovens para as ruas, em busca de prover sua sobrevivência no trabalho -, a doutrina da situação irregular passou a ser combatida pela sociedade civil organizada, políticos e profissionais ligados aos campos do direito, jornalismo, assistência social, psicologia, técnicos da Fundação Nacional do Bem-Estar do Menor (FUNABEM) ${ }^{7}$ etc. Todos assinalavam o excessivo rigor de maus-tratos físicos, a repressão, a violação dos direitos (por exemplo, a tortura), a permissão do trabalho infantil, a exploração sexual e o extermínio, entre outros mecanismos utilizados na disciplinarização desses indivíduos (XAVIER, 2008).

Em meio a um considerável quadro de denúncias contra essa doutri-

\footnotetext{
${ }^{6}$ Segundo Rizzini (1997), até o ano de 1980,64,5\% das crianças e adolescentes com idade inferior a 19 anos compunham a população urbana. Das 27 milhões e 690 mil famílias, $48 \%$ se caracterizavam por ter como chefe uma pessoa com rendimento mensal inferior a 2 salários mínimos, além de abrigar $51,2 \%$ das crianças e adolescentes menores de 19 anos. Se a esse dado fossem acrescentados os sem-rendimentos, poderia ser considerada a existência de 32 milhões de crianças e adolescentes atingidos pela carência socioeconômica na década de 1980.

${ }^{7}$ Órgão normativo que tinha a finalidade de criar e implementar a política nacional de bem-estar do menor, através da elaboração de diretrizes políticas e técnicas (RIZZINI, 1997).
} 
na, havia uma intensa mobilização da sociedade civil que discordava tanto do modelo de atendimento instituído no Código de Menores quanto da ausência de políticas de atendimento efetivas e preventivas, voltadas ao cuidado das crianças e dos adolescentes no país. Essas mobilizações criaram o projeto do que se denominou "práticas alternativas comunitárias" ${ }^{8}$, as quais desenvolviam experiências alternativas com as crianças de rua. Tratava-se de uma prática pedagógica que tinha como um de seus princípios a valorização do contexto social no qual esses sujeitos estavam inseridos. Dentre essas experiências, podemos citar a realizada pela República do Pequeno Vendedor ${ }^{9}$ em Belém, Pará. Conforme relata Bruno Sechi:

Surgem às margens do atendimento oficial praticado pela FUNA$B E M$, experiências com o atendimento de meninos e meninas de rua em situação de extrema pobreza. Essas experiências foram influenciadas pela concepção pedagógica de Paulo Freire. Por meio de práticas pedagógicas de educação libertadora enquanto um meio de transformação social, defendia o protagonismo infanto-juvenil. A república do Pequeno Vendedor foi pioneira nessas experiências de atendimento, pois no final da década de 1970 já tinha um projeto político pedagógico bem estruturado, uma certa caminhada e até mesmo um certo posicionamento político em relação à FUNABEM. Esses não contavam com apoio do governo e nem de organismos internacionais e também não tinham convênios nem com o governo, nem com a FUNABEM e com a FUBESP. Eles recusavam recursos, pois não concordavam com os termos estabelecidos para o repasse de verbas às entidades de atendimento, uma vez que era necessário se adequar à Política Nacional de Bem-Estar do Menor instituída pela Funabem. Diante dessas condições a República decidiu constituir-se um movimento independente e autônomo (informação verbal ${ }^{10}$ ).

\footnotetext{
${ }^{8}$ República do Pequeno Vendedor em Belém, PA; Pastoral do Menor em São Paulo; Fórum dos Direitos das Crianças e dos Adolescentes (Fórum DCA) no Rio de Janeiro.

9 Suas atividades tiveram início por meio de um grupo de jovens ligados à Escola Salesiana do Trabalho, que partiu de reflexões sobre a população carente de Belém, passando a desenvolver atividades com crianças e adolescentes trabalhadores de rua; um processo inspirado na doutrina salesiana criada por D. Bosco. A ação do movimento buscou, a partir da situação vivenciada pelos pequenos trabalhadores de rua, se constituir em um espaço no qual todos poderiam participar. Assim, o movimento, através de uma prática social inovadora para a época e procurando dar respostas à situação de carência das crianças e adolescentes trabalhadores de rua, organizou projetos e ações que se mostraram e se mostram bastante representativas para a vida das meninas e meninos de rua. Atualmente intitulado República de Emaús, o movimento atende não apenas aos meninos trabalhadores de rua, mas, também, a crianças e adolescentes em situação de risco pessoal e social. Entre as atividades desenvolvidas, estão oficinas profissionalizantes, educação de rua, inserção no mercado formal de trabalho e atividades de cultura, esporte e lazer (ABREU, 2010).

${ }^{10}$ Entrevista concedida pelo Padre Bruno Sechi às pesquisadoras (Belém, PA, 15 mar. 2018).
} 
Nossa compreensão é de que, nesse período, o trabalho com os meninos e meninas de rua desenvolvido pela República do Pequeno Vendedor teve sua ação reconhecida enquanto instituição componente dos movimentos sociais, uma vez que se posicionava criticamente quanto às ações desenvolvidas pelo Estado a partir do Código de Menores. As práticas alternativas se desenvolviam com o envolvimento dos educadores no contexto socioeconômico em que os meninos estavam inseridos.

Assim, esse movimento se tornou um espaço de enfrentamento dos problemas vivenciados por essa parcela da sociedade paraense, além de um espaço de organização e articulação com a premissa de estruturar núcleos de trabalho através de metodologias participativas, nas quais se priorizava o envolvimento de todos, enquanto um meio de aprofundamento e reflexão da condição social, tanto do seu trabalho cotidiano quanto de sua vida nas ruas (ABREU, 2010; PEREIRA, 1998). Nesse contexto, a República do Pequeno Vendedor teve um papel fundamental na luta pelos direitos da criança e do adolescente, se tornando empreendedora de experiências comunitárias na área infanto-juvenil e de práticas alternativas, representando uma oposição necessária às ações instituídas pelo Estado.

Para Xavier (2008), no início dos anos 1980, vários fatores impulsionaram a articulação de grupos e instituições voltados à problemática da infância e adolescência no país. Especificamente, em relação a crianças e adolescentes, as desaprovações estavam centradas na exaltação da fraca proteção jurídica, em meio a um discurso pautado no aspecto classista do "menor em situação irregular". Essas discordâncias adquiriram centralidade devido ao debate internacional feito nesse período, particularmente, no ano de 1979, momento em que UNICEF e a Organização Mundial da Saúde (OMS) anunciam o "ano internacional da criança". A partir daí, foram organizados vários encontros, seminários e fóruns de debates internacionais, nos quais se passou a questionar a noção de "criança no mundo" e a possibilidade de torná-las categoria "universal", episódio esse que favoreceu o fortalecimento dos discursos protetivos de crianças e adolescentes e a instituição de políticas nacionais e internacionais sob essa perspectiva (MEIRELES, 2013, p. 159).

Assim, em meio ao clima institucional e à intensificação das pressões sociais, o governo brasileiro elaborou uma proposta de ação conjunta entre a Secretaria de Ação Social do Ministério da Previdência e Assistência Social (SAS), FUNABEM e UNICEF, com o objetivo de construir uma base de conhecimentos para auxiliar os órgãos executores a criarem novas políticas para tratar da problemática dos meninos e meninas de rua. O governo agregou o apoio 
de entidades que já tinham experiências de ensino-aprendizagem com essa população, a fim de conhecer as experiências consideradas bem-sucedidas, a demanda existente, as metodologias e os recursos utilizados nas experiências. Dentre as entidades escolhidas, Pereira (1998, p. 123) destaca...

O trabalho desenvolvido pela República do Pequeno Vendedor e de mais quatro outras experiências (Centro Salesiano do Menor - Cesam, de Belo Horizonte/MG; Salão do Encontro, de Betim/ MG; Cerâmica Educacional Boa Nova, de Ipameri/GO; Centro de Orientação Sócio-Educativa do Menor Trabalhador - COSEMT, de São José dos Campos/SP), ambas já tinham de um total setenta experiências levantadas pelo projeto, se constituíram em referências de ação, em pólos irradiadores de uma nova metodologia de trabalho, de um novo modo de tratar e atender às necessidades/ direitos de crianças e adolescentes, ou seja, a combinação dos aspectos atendimento/denúncia/defesa de direitos no cotidiano de suas práticas, forjando um novo desenho das políticas públicas destinadas à infância e à adolescência, baseado no paradigma doutrina da proteção integral, expresso nas principais convenções e recomendações internacionais.

O Projeto Alternativo de Atendimento a Meninos de Rua, intitulado "Aprendendo com quem faz", se configurava como uma estratégia de ensino-aprendizagem, denominada de "semitágios"11. Neles, se desenvolviam atividades de produção e socialização de materiais, cujo foco era proporcionar ao movimento popular o aprofundamento de conhecimentos e experiências para novos programas de atendimento e para a formação de lideranças. De acordo com Bruno Sechi:

Essa estratégia só foi possível após vários debates entre os parceiros e as entidades não-governamentais responsáveis pelos programas alternativos. A perspectiva das entidades não era a institucionalização do projeto e o entendimento aos Estados e Municípios como um modelo a ser adotado, mas como uma referência, um ponto de partida para o despertar das mobilizações sociais, pois a partir do conhecimento da sua realidade local, do envolvimento de pessoas da comunidade e agentes institucionais, conseguiríamos viabilizar uma proposta de mo-

\footnotetext{
${ }^{11}$ Palavra resultante da fusão da palavra seminário com a palavra estágio, que permitia a reflexão conjunta e aprofundada sobre uma experiência na qual o grupo tinha oportunidade de imergir de forma completa (COSTA, 1994).
} 
bilização coletiva em torno desses programas alternativos, a fim de conscientizar todos os envolvidos de que a política para a infância deveria alcançar o patamar de direitos e não ficar apenas no plano das necessidades (informação verbal).

Entretanto, segundo Tommasi (1997), esse projeto se caracterizou apenas na transferência de responsabilidades do poder público à comunidade local, com vistas a prestar assistência financeira, uma vez que não lhes interessava a execução de uma política institucional voltada ao problema dos meninos e meninas de rua, apenas se preocupavam com a fiscalização dos menores. Nesse contexto, o governo se utilizava do discurso ideológico de superação dos problemas sociais para implementar projetos para a formação profissional, com foco no mercado de trabalho, mas, apenas em alguns serviços que não exigiam uma formação específica - como, por exemplo, engraxate, carregador de supermercado, vendedor de picolés, flanelinha etc. Diante disso, não havia espaço para a comunidade questionar o poder público sobre as desigualdades sociais, falta de políticas sociais voltadas à população-e, em especial, às crianças e adolescentes -, como saúde, moradia, educação, emprego e renda.

Nesse contexto, foram as entidades integrantes do Projeto Alternativas de Atendimento a Meninos de Rua que mobilizaram ações políticas em defesa desses, resistiram e aproveitaram a iniciativa para estabelecer um intercâmbio entre todos aqueles que trabalhavam com os meninos e meninas de rua pelo Brasil afora. Esse grupo foi o embrião do que mais tarde se configuraria como uma grande mobilização social que deu origem ao ECA. Esses grupos inverteram a lógica do que havia sido estabelecido pelo Estado com o Projeto Alternativas de Atendimento. Segundo o Padre Bruno Sechi:

Nesse seminário intitulado "Alternativo de Atendimento aos Meninos e Meninas de Rua", financiado pelo governo, objetivava construir um grande projeto nacional, que se constituiria em referências de ações e polos irradiadores de uma nova metodologia de trabalho, através de uma nova forma de tratar e atender às necessidades dos direitos de crianças e adolescentes. Esse inicialmente seria um projeto institucional, entretanto, acabou se configurando como um programa de cunho assistencialista, que trabalhava a questão dos meninos e meninas de rua desarticulado dos problemas socioeconômicos do país. A partir desse entendimento, nós acabamos virando a mesa, e pedimos o apoio do UNICEF, para criar um intercâmbio dessas experiências pelas regiões do Brasil. A partir disso, começaram a se articular uma teia de experiências, formando uma rede de atendimento com 
interações de grupos de educadores com experiência com os meninos e meninas de rua. Além disso, o projeto ocorreu mais intensamente e, no início dos anos 1980, já somava mais de 400 experiências que estavam interagindo pelo Brasil afora. Foi quando os educadores que compunham essas entidades, por meio de uma teia de relações, decidiram desvincular-se desse projeto e fazer um movimento à parte, sem apoio do governo, eles decidiram fazer um movimento independente e autônomo. [...] e pediram o apoio do UNICEF para possibilitar um encontro nacional de educadores que objetivava lançar as bases de um movimento da sociedade civil, que acabou se chamando Movimento Nacional dos Meninos e Meninas de Rua - MNMMR (informação verbal).

Toda essa movimentação de luta e mobilizações por melhores condições de vida para os meninos e meninas de rua, ocorrida no início da década 1980, se interligava a outras demandas e carências populares, como o movimento negro, movimento pela reforma agrária, movimento feminista, em torno dos quais o Movimento Nacional Meninos e Meninas de Rua (MNMMR) se integrou, ampliando e fortalecendo a aliança que se consolidava em prol da garantia de direitos e do respeito à dignidade humana.

Assim, ocorreu em Brasília, no ano de 1984, o I Seminário Latino-Americano sobre Alternativas Comunitárias para Meninos de Rua, promovido pelo UNICEF e pelo Ministério da Previdência e Assistência Social do Brasil. Nele, foi realizado o intercâmbio de experiências entre diferentes países, o que acabou contribuindo ainda mais para a reflexão conjunta sobre a necessidade de superação do modelo assistencialista. Esse seminário ficou marcado por intensas críticas ao sistema correcional-repressivo do Código de Menores e da FUNABEM (LONGO, 2010).

Vale destacar o papel desempenhado pelas lutas e mobilizações do MNMMR, que impactou nesse período como uma das mobilizações populares mais marcantes no cenário de debates em torno da questão relacionada à criança e ao adolescente no país. No ano seguinte, em 1986, realizou-se "o I Encontro Nacional dos MNMMR, em Brasília e contou com a participação de 432 meninos e meninas de rua" (PEREIRA, 1998, p. 98).

Nessa conjuntura, a abertura política vivenciada no período pós-ditadura militar possibilitou a saída de movimentos sociais, atores políticos e sindicatos da clandestinidade, favorecendo sua rearticulação com a sociedade civil. Nesse momento, ainda, as pastorais, associações de moradores e outras entidades saíram às ruas, criticaram duramente o Estado por melhores condições de vida e passaram a reivindicar políticas públicas para todos. 


\section{Menoristas x Estatutistas: do Estado punitivo ao Estado protetivo}

Na conjuntura que se construiu, havia dois grupos que se mobilizavam em defesa da criança e adolescentes no país. Esses grupos denominavam-se menoristas e estatutistas. Os menoristas defendiam a manutenção do Código de Menores e se propunham a regulamentar a situação das crianças e adolescentes por meio do paradigma da "Situação Irregular", o qual os mantinha como objeto de proteção especial e servia como "instrumento de controle social, quando eram vítimas de omissão e transgressão da família, da sociedade e do Estado em seus direitos básicos" (PEREIRA, 1998, p. 71), ficando assim sob a proteção judicial. A linguagem utilizada pelos menoristas tinha como premissa o combate ao subdesenvolvimento e a focalização das intervenções com as crianças e adolescentes pobres e suas famílias, tidas como ameaça ao futuro do país. Entretanto, esse grupo pouco discutiu a questão dos direitos das crianças e dos adolescentes, tampouco as desigualdades sociais presentes no contexto social dessa população (PEREIRA, 1998).

Já os estatutistas defendiam uma grande mudança no Código de Menores por meio da instituição de novas e amplas formulações para os direitos das crianças e adolescentes. Esse novo código passaria a ser um instrumento de desenvolvimento social, voltado para o conjunto da população infanto-juvenil do país, garantindo proteção especial a esses segmentos como um todo, fazendo com que passassem a ter seus direitos protegidos pela premissa jurídica da Proteção Integral. O grupo dos estatutistas era referenciado socialmente devido à sua articulação orgânica com os diversos setores da sociedade civil, visto que possuíam representação, capacidade técnica e importantes políticas de atuação - como, por exemplo, o MNMMR e a Pastoral da Criança, criada em 1983, em nome da Conferência Nacional dos Bispos do Brasil (CNBB), envolvendo forte militância proveniente dos movimentos sociais da Igreja católica.

Constata-se, portanto, que menoristas e estatutistas apresentaram propostas diferenciadas para o atendimento à criança e ao adolescente, o que se evidencia a partir da legislação resultante, comentada no Quadro 1. 
Quadro 1 - Paradigma da situação irregular x Paradigma da proteção integral

\begin{tabular}{|c|c|c|}
\hline & $\begin{array}{c}\text { Lei } 6.697 / 1979 \\
\text { (Código de Menores) }\end{array}$ & $\begin{array}{c}\text { Lei 8.069/1990 } \\
\text { (Estatuto da Criança e do } \\
\text { Adolescente) }\end{array}$ \\
\hline $\begin{array}{l}\text { Princípios da } \\
\text { política de } \\
\text { atendimento }\end{array}$ & $\begin{array}{l}\text { Através da política } \\
\text { de assistência social, } \\
\text { implementada com forte } \\
\text { caráter assistencialista, } \\
\text { compensatório e centralizado. } \\
\text { Sem articulação com as } \\
\text { demais políticas sociais }\end{array}$ & $\begin{array}{l}\text { Ações de atenção se dão nos } \\
\text { municípios e são por eles } \\
\text { controladas. A formulação } \\
\text { da política conta com a } \\
\text { participação da sociedade } \\
\text { organizada em nível } \\
\text { municipal, estadual e federal }\end{array}$ \\
\hline $\begin{array}{l}\text { Concepção de } \\
\text { criança e do } \\
\text { adolescente }\end{array}$ & $\begin{array}{l}\text { Menor em situação irregular, } \\
\text { objeto de medidas judiciais }\end{array}$ & $\begin{array}{l}\text { Sujeito de direitos e pessoa } \\
\text { em condição peculiar de } \\
\text { desenvolvimento }\end{array}$ \\
\hline $\begin{array}{c}\text { Concepção } \\
\text { político } \\
\text { administrativa }\end{array}$ & $\begin{array}{l}\text { Instrumento de controle } \\
\text { social }\end{array}$ & $\begin{array}{l}\text { Instrumento de } \\
\text { desenvolvimento social }\end{array}$ \\
\hline Objetivo & $\begin{array}{l}\text { Dispunha sobre a assistência a } \\
\text { menores entre zero e dezoito } \\
\text { anos, que se encontravam em } \\
\text { situação irregular, e entre } 18 \\
\text { e } 21 \text { anos, nos casos previstos } \\
\text { em lei }\end{array}$ & $\begin{array}{l}\text { Garantia dos direitos } \\
\text { pessoais e sociais, através } \\
\text { da criação de oportunidades } \\
\text { e facilidades com vistas ao } \\
\text { desenvolvimento físico, } \\
\text { mental, moral, espiritual } \\
\text { e social em condição de } \\
\text { liberdade e dignidade }\end{array}$ \\
\hline $\begin{array}{l}\text { Mecanismos de } \\
\text { participação }\end{array}$ & $\begin{array}{l}\text { Institui o Conselho de } \\
\text { Assistência e Proteção } \\
\text { ao Menores, como } \\
\text { associação de utilidade } \\
\text { pública, com personalidade } \\
\text { jurídica. As funções dos } \\
\text { Conselheiros, nomeados } \\
\text { pelo Governo, eram auxiliar } \\
\text { o Juízo de Menores, sendo os } \\
\text { Conselheiros denominados } \\
\text { Delegados da Assistência e } \\
\text { Proteção aos Menores }\end{array}$ & $\begin{array}{l}\text { Institui instâncias colegiadas } \\
\text { de participação (Conselhos } \\
\text { de Direitos, paritários Estado } \\
\text { e Sociedade Civil), nas três } \\
\text { instâncias da administração, } \\
\text { e cria no nível municipal } \\
\text { os Conselhos Tutelares, } \\
\text { formado por membros } \\
\text { escolhidos pela sociedade } \\
\text { local e encarregados de zelar } \\
\text { pelos direitos de crianças e } \\
\text { adolescentes }\end{array}$ \\
\hline
\end{tabular}




\begin{tabular}{|l|l|l|}
\hline & $\begin{array}{l}\text { Participação em redes de } \\
\text { proteção, participação } \\
\text { social (ONGs nacionais e } \\
\text { Forma de Gestão } \\
\text { internacionais, Governo } \\
\text { Hierarquização piramidal do } \\
\text { controle social: centralismo } \\
\text { estatal (autoridade policial, } \\
\text { judiciária e administrativa) }\end{array}$ & $\begin{array}{l}\text { Municipais, Conselhos } \\
\text { Tutelares, Fundos e } \\
\text { Conselhos de Direito da } \\
\text { Criança e do Adolescente, } \\
\text { família, comunidade etc.) }\end{array}$ \\
\hline
\end{tabular}

FONTE: ELAABORADO PELAS AUTORAS COM BASE NA LEGISLAÇÃo (BRASIL, 1979, 1990).

Considerando o quadro, é possível dizer que ambos os grupos possuíam como premissa as demandas sociais referentes à questão da infância brasileira, especificamente, a problemática dos meninos e meninas de rua e a possiblidade de mudanças frente ao clima institucional da década de 1980, na qual a legislação tratava a criança e o adolescente por meio de medidas de proteção, não os considerando como sujeitos de direitos. Enquanto isso, o ECA lutava por justiça social, para esses que sempre viveram à margem do direito, pretendendo instituir o sistema de garantia de direitos e o princípio da proteção integral enquanto princípio de dignidade humana, a fim de lhes garantir o desenvolvimento integral em condições de liberdade e dignidade.

A abrangência desse tema proporcionou o afloramento de intensas discussões envolvendo infância e adolescência em todo o país. Tal fortalecimento ampliou a rede de mobilização, na qual foram inseridas outras instâncias para além de entidades da sociedade civil, como centros de estudos e pesquisas de universidades, centros de defesa da criança etc. Cumpre lembrar ainda que, a partir dessas manifestações, foi constituíd o o Fórum DCA, que teve importante contribuição na luta em defesa dos direitos das crianças e adolescentes.

Esses movimentos e embates ideológicos se desenrolaram em meio ao processo histórico de redemocratização e mobilização pela garantia dos direitos sociais a nível nacional, o que fez com que a sociedade civil se organizasse para participar da elaboração da Constituição Federal de 1988. Nesse processo duas campanhas tiveram relevância: Criança Constituinte (1986) e Criança Prioridade Nacional (1987).

A primeira campanha contou com o apoio do Ministério da Educação 
e reuniu vários setores governamentais e da sociedade civil, como "[...] UNICEF, Conselho Nacional dos Direitos da Mulher, Ordem dos Advogados do Brasil, Frente Nacional de Defesa dos Direitos da Criança, Movimento Nacional de Meninos e Meninas de Rua [...]" (PEREIRA, 1998, p. 101). Essa campanha objetivava auxiliar o debate sobre questões referentes à criança e ao adolescente, garantindo-lhes um espaço específico no ordenamento jurídico brasileiro.

Já em 1987, foi criada a campanha Criança Prioridade Nacional, envolvendo organizações, representantes das diversas forças sociais presentes no campo da infância e da adolescência, numa ação conjunta e articulada pela instituição de um novo ordenamento legal e institucional. Em março do ano seguinte, essas organizações promoveram, por meio do Fórum DCA, uma ampla mobilização para a aprovação de uma emenda que assegurasse às crianças e aos adolescentes prioridade absoluta na implantação de políticas públicas que viessem a garantir a essa população o gozo de seus direitos (PEREIRA, 1998).

Pereira (1998) relata que, dentre as ações do Fórum DCA, teve destaque a definição da concepção de criança e a estruturação de política pública voltada a crianças e adolescentes, visto que o Fórum conseguiu articular diversas representações sociais, como entidades de renome nacional, em busca da incorporação, pela Assembleia Constituinte, de uma proposta relativa aos direitos de crianças e adolescentes, encontrando amparo nas articulações estaduais e municipais ligadas ao movimento social. Isso ajudou para que, nessas instâncias, fossem organizados os fóruns regionais, de maneira a continuar os debates e, ao mesmo tempo, construir as Constituições Estaduais e as Leis Orgânicas Municipais. A partir daí, iniciava-se o processo de elaboração do projeto de lei para regulamentação dos artigos referentes à política para a infância (artigos 204, 227 e 228) na Constituição Federal (PEREIRA, 1998).

Dessa maneira, esses grupos, por meio das articulações feitas a nível nacional, estadual e municipal, em convergência com os movimentos sociais que buscavam a garantia de direitos para toda a população, sistematizavam as contribuições e sugestões de propostas relativas aos/e feitas pelos meninos e meninas de rua em vários estados para a criação do ECA; ao passo que a Assembleia recebia tais propostas e as reformulava no formato da lei. Santos (1992, p. 69) rememora que "foram elaboradas cerca de seis versões até o substitutivo da câmara" e, partir daí, se realizou em todo o território nacional mobilizações em diversos setores da sociedade civil para a aprovação do ECA, em 1990. 


\section{Considerações finais}

Este texto discute a contribuição dos movimentos sociais para o fortalecimento e a institucionalização de uma política mundialmente considerada como uma das mais avançadas no atendimento a crianças e adolescentes, o Estatuto brasileiro da Criança e do Adolescente, Lei no 8.090/1990. Esta normativa reafirmou o conceito já estabelecido na Constituição Federal de 1988 , artigo 227, que consagra o tratamento a crianças e adolescentes como sujeitos de direitos.

É importante considerar a contribuição das iniciativas mobilizadoras em todo o território nacional, como a República do Pequeno Vendedor, em Belém, o Movimento Nacional Meninos e Meninas de Rua, Fórum DCA, fóruns estaduais e municipais, centros de pesquisas das universidades, as entidades, associações de moradores, pastorais eclesiásticas, juristas, sindicatos, entre outros, os quais tiveram intensa participação no processo de luta pela aprovação do estatuto e pela mudança no paradigma da criança em situação irregular para o paradigma da criança como prioridade absoluta.

Muitos foram os caminhos percorridos para a institucionalização dos direitos positivados no ECA. Ainda que tal visibilidade não seja suficientemente destacada, esse percurso esteve diretamente atrelado aos movimentos sociais que se colocaram ativamente a favor da garantia e efetivação do direito previsto em nossa Carta Magna. As intensas mobilizações sociais no país evidenciaram uma história de busca por autonomia, por reconhecimento político e social e por direitos.

O ECA instituiu a doutrina da Proteção Integral e trouxe contribuições significativas para as políticas de atendimento à criança e ao adolescente. A primeira a legitimar a sua execução ocorre a partir de uma "gestão articulada entre o Estado, família a sociedade" (MEIRELES, 2013, p. 160); a segunda se refere ao caráter universal das políticas de atendimento - ou seja, ao invés de atender apenas a crianças e adolescentes em "situação irregular", o alvo das intervenções passou a ser todo indivíduo com idade de zero a 18 anos.

No entanto, ainda é possível constatar recorrentes violações aos direitos das crianças e adolescentes, a partir de evidências que impactam na efetividade material da sua condição de sujeitos de direito. Como adverte Costa, "a realidade empírica não pode ser confundida com a normativa, pois o fato de se afirmar que os direitos estão positivados não os faz existir na materialidade do contexto social" (2012, p. 31).

Considerando os achados da revisão bibliográfica e da entrevista com 
o padre Bruno Sechi, as políticas públicas de atendimento na área da infância e da adolescência progrediram de forma relevante a partir do ECA. Ainda assim, sua efetivação continua a se constituir um dos maiores desafios para a sociedade brasileira. Tal tarefa deve ser enfrentada com a garantia do constante fortalecimento da rede de proteção social, preconizada por um sistema de garantia de direitos que articule ações entre os diferentes campos de atendimento - saúde, educação, assistência, justiça, poder público - e que objetive o cumprimento dos direitos fundamentais, inerentes à existência humana.

\section{Referências}

ABREU, W. F. O trabalho de socialização de meninos de rua em Belém do Pará: um estudo sobre a República Pequeno Vendedor. 2010. Tese (Doutorado em Educação) - Pontifícia Universidade Católica do Rio de Janeiro, Rio de Janeiro, 2010.

BRASIL. [Código de Menores (1979)]. Lei no 6.697, de 10 de outubro de 1979. Institui o Código de Menores. Brasília, DF, 1979. Disponível em: http://www. planalto.gov.br/ccivil_03/leis/1970-1979/L6697impressao.htm. Acesso em: 22 maio 2010.

BRASIL. [Constituição (1988)]. Constituição da República Federativa do Brasil de 1988. Brasília, DF, 1988. Disponível em: http://www.planalto.gov.br/ccivil_03/Constituicao/Constituicao.htm. Acesso em: 10 mar. 2019.

BRASIL. [Estatuto da Criança e do Adolescente (1990)]. Lei no 8.069, de 13 de julho de 1990. Dispõe sobre o Estatuto da Criança e do Adolescente e dá outras providências. Brasília, DF, 1990. Disponível em: http://www. planalto.gov. br/ccivil_03/leis/L8069Compilado.htm. Acesso em: 22 maio 2010.

COSTA, A. C. G. De menor a cidadão. In: COSTA, A. C. G.; MENDEZ, É. G. (org.). Das necessidades aos direitos. São Paulo: Malheiros, 1994. pt. II., p. 121-145. (Série Direitos das Crianças, n. 4).

COSTA, A. P. C. Os adolescentes e seus direitos fundamentais: da invisibilidade à indiferença. Porto Alegre: Livraria do Advogado, 2012.

FUNDO DAS NAÇÕES UNIDAS PARA A INFÂNCIA. \#ECA25anos: avanços e desafios para a infância e a adolescência. [S. I.]: UNICEF, 2015.

LONGO, I. Ser criança e adolescente na sociedade brasileira: passado e presente da história dos direitos infanto juvenis. In: CONGRESSO INTERNACIONAL DE PEDAGOGIA SOCIAL, 3., 2010, São Paulo. Anais... São Paulo: ABES, 2010. p. 1-20. 
MACIEL, F. Todo trabalho é digno?: um ensaio sobre moralidade e reconhecimento na modernidade periférica. In: SOUZA, S. (org.). A invisibilidade da desigualdade brasileira. Belo Horizonte: Ed. UFMG, 2006. p. 285-319.

MARTINS, J. S. Regimar e seus amigos: a criança na luta pela terra e pela vida. In: MARTINS, J. S. (org.). O massacre dos inocentes: a criança sem infância no Brasil. São Paulo: Hucitec, 1991. p. 51-80.

MEIRELES, M. O ECA e os desafios da universalização da infância. In: MEIRELES, M. et al. (org.). Ensino de sociologia: direitos humanos, sociais, educação e saúde. Porto Alegre: Evangraf, 2013. p. 151-170.

MORAES, A. F.; CARVALHO, S. R. O Estatuto da Criança e do Adolescente e instituições: consensos e conflitos. Revista CADE-FMJ, Rio de Janeiro, v. 4, p. 71-94, 2002.

PEREIRA, R. F. S. Movimentos de defesa dos direitos da criança e adolescente: do alternativo ao alternativo. 1998. Dissertação (Mestrado em Serviço Social) - Pontifícia Universidade Católica de São Paulo, São Paulo, 1998.

PINI, F. R. O. Estatuto da Criança e do Adolescente: 25 anos de história. In: VIEIRA, A. L.; PINI, F.; ABREU, J. (org.). Salvar o Estatuto da Criança e do Adolescente. São Paulo: Instituto Paulo Freire, 2015. p. 10-13.

RIZZINI, I. O século perdido: raízes históricas das políticas públicas para a infância no Brasil. Rio de Janeiro: Ed. Universitária Santa Úrsula, 1997.

SANTOS, B. R. A implantação do Estatuto da Criança e do Adolescente. In: PEREIRA JUNIOR, A.; BEZERRA, J. L.; HERINGER, R. (org.). Os impasses da cidadania: infância e adolescência no Brasil. Rio de Janeiro: IBASE, 1992. p. 66-79.

SANTOS, O. J. Pedagogia dos conflitos sociais. Campinas: Papirus, 2004.

TOMMASI, L. Em busca da identidade: as lutas em defesa dos direitos da criança e do adolescente no Brasil e a questão da participação. 1997. Tese (Doutorado em Sociologia) - Université de Paris I, Paris, 1997.

VOLPI, M. Sem liberdade, sem direitos: a privação da liberdade na percepção do adolescente. São Paulo: Cortez, 2001.

XAVIER, A. As ações, lutas, estratégias e desafios do movimento de defesa dos direitos das crianças e adolescentes no Espírito Santo. 2008. Dissertação (Mestrado em Educação) - Universidade Federal do Espírito Santo, Vitória, 2008.

Data de recebimento: 28.10 .2018

Data de aceite: 03.06.2019 